\title{
Working with the Homeless: The Psychiatric Resident's Experience
}

\author{
Ronald J. Koshes, MD \\ Walter Reed Army Medical Center, Washington DC \\ Lance D. Clawson, MD \\ Walter Reed Institute of Research, Washington DC
}

Follow this and additional works at: https://jdc.jefferson.edu/jeffjpsychiatry

Part of the Psychiatry Commons

\section{Let us know how access to this document benefits you}

\section{Recommended Citation}

Koshes, MD, Ronald J. and Clawson, MD, Lance D. (1989) "Working with the Homeless: The Psychiatric Resident's Experience," Jefferson Journal of Psychiatry. Vol. 7 : Iss. 1 , Article 9.

DOI: https://doi.org/10.29046/JJP.007.1.006

Available at: https://jdc.jefferson.edu/jeffjpsychiatry/vol7/iss $1 / 9$

This Article is brought to you for free and open access by the Jefferson Digital Commons. The Jefferson Digital Commons is a service of Thomas Jefferson University's Center for Teaching and Learning (CTL). The Commons is a showcase for Jefferson books and journals, peer-reviewed scholarly publications, unique historical collections from the University archives, and teaching tools. The Jefferson Digital Commons allows researchers and interested readers anywhere in the world to learn about and keep up to date with Jefferson scholarship. This article has been accepted for inclusion in Jefferson Journal of Psychiatry by an authorized administrator of the Jefferson Digital Commons. For more information, please contact: JeffersonDigitalCommons@jefferson.edu. 


\title{
Working With The Homeless: The Psychiatric Resident's Experience
}

\author{
Ronald J. Koshes, M.D. \\ Lance D. Clawson, M.D.
}

HOMELESSNESS IN WASHINGTON, D.C.

The latter years of the twentieth century have witnessed a phenomenon unparalleled since the depression of the 1930's. Legions of homeless, disadvantaged, often mentally ill poor have emerged thronging cities, crowding public places and presenting perplexing complex, social, political, economic, and medical/psychiatric service delivery issues (1). Counting the homeless, and among them the mentally ill homeless, is a task fraught with difficulty, as some studies have illustrated (2,3). Estimates of mental illness among the nation's homeless range from $10 \%$ to $70 \%$ (4). In the District of Columbia, there are an estimated six to seven thousand homeless. Of these, in $1988,36 \%$ were felt to be mentally ill (5).

The increasing numbers of homeless and mentally ill street people are the result of a complex interweaving of political and economic factors including housing policy, urban gentrification, changing requisite job skills in a changing economy, and deinstitutionalization (6). Regardless of their origin, the chronically mentally ill (CMI) homeless present as a population with diverse acute medical and psychiatric needs.

Delivering services to this increasing "underclass" in the United States has mobilized the non-medical private sector in a attempt to cope with the homeless' perplexing needs. This "shelter industry" has repeatedly called for medical and psychiatric support to help provide care to the homeless urban poor, and their medical care needs present an opportunity for training in community and emergency psychiatry unparalleled in recent decades (7). What follows is a description of the planning and implementation of an elective for fourth year psychiatry residents designed to expose them to this underserved population.

\section{BEGINNING A SERVICE NETWORK}

In late 1986, the Washington Psychiatric Society's Committee for the Homeless was formed. The first task of the Committee was to review the current literature in order to investigate the conceptual evolution of mental health care delivery to the chronic mentally ill homeless. Fortunately, the Mendota Project served as a model for creating within the community those lost state hospital "institutional" structures that had provided a social, medical, housing, and mental health management system for the mentally ill before deinstitutionaliza- 
tion (8). In part, the Committee was conceived as an agency which would assist in recruiting and coordinating mental health manpower into the understaffed D.C. shelter system. Subsequent goals of the Committee were to assess the psychiatric needs of the system, determine what shelters were in place, what their psychiatric needs were, and how these needs could be most effectively met. Armed with this knowledge the Committee undertook to become familiar with the evolving infrastructure in the Washington metropolitan area devoted to delivering care to the CMI homeless. Shelters were visited and contacts established with program directors. The Emergency Psychiatric Response Division of the D.C. General Hospital was visited and health care system needs were reviewed with the Director and the staff. It soon became apparent that providing psychiatric services to this developing system would provide an invaluable training experience in community and emergency psychiatry for psychiatric residents in the metropolitan Washington area.

\section{DESIGNING A CURRICULUM}

In early 1987, interested psychiatrists were recruited through the Washington Psychiatric Society's Newsletter to volunteer their time and expertise to begin to work with the CMI homeless. Through the efforts of an interested faculty member at the Uniformed Services University of the Health Sciences, we were enlisted in the effort to determine just how a resident might participate in delivering psychiatric services through the shelter system, and at the same time receive training in community and emergency psychiatry. After several visits to one shelter, we felt that the training experience could not simply consist of delivering psychiatric care to the homeless, but also should emphasize a multidimensional, multidisciplinary interaction in the community. From this came the ideas of an integrated curriculum; one that could break the experience down into its component parts, each conceptualizing a specific skill requisite, yet mindful of promoting a cohesive experience. The overall document was to be used as an academic guide in navigating one's way through the diverse clinical experience.

The curriculum itself is divided into five basic areas of study, each with its own performance objectives and goals clearly laid out, as well as a reference section citing pertinent literature. Although the trainee has the opportunity to emphasize any or all of these five areas, an attempt is made during the course of the 6 to 12 month elective to expose the trainees to all five. These areas are:
A) Training in Community and Emergency Psychiatry
B) Shelter Service Delivery Issues
C) Research on the Homeless
D) Socio-Cultural Aspects of Homelessness
E) Legal Advocacy Issues

Sections A and B are the clinical core of the shelter experience, and all 
participants are expected to master this part of the curriculum. Section A is subdivided into "History and Mental Status Examination," "The Patient in Crisis," "Substance Abuse," and "Involuntary Hospitalization and Disposition." Section B is in turn subdivided into "Natural History and Treatment Planning," "Treatment Strategies," and "Group Therapy and Staff Development." As an example, the subsection "The Patient in Crisis," including references, from training area $\mathrm{A}$, is reproduced in Table 1 .

The academic year begins with an initial tour of all the possible shelter work sites to aid the resident in finding a niche in the care delivery system. Written descriptions of all the shelter programs, the Mental Health Law Project and the Emergency Psychiatric Response Division also help the resident choose an appropriate site. Throughout the elective, group supervision is provided for the residents for purposes of discussing individual cases, systems issues, and staff development problems. Additionally, once per month a visiting lecturer presents various topics on legal, sociologic, emergency psychiatry, political policy, and community mental health issues which pertain to working with the homeless. The aim of this format is to give the young psychiatrist exposure to this population, the particular clinical aspects of their care, and the overall multidimensional nature of the work. As a result, each participant is encouraged first

TABLE 1.

\section{Sample Section of Curriculum}

... 2) Management Issues

a) The Patient in Crisis

Performance Objectives: The resident will demonstrate, by clinical competence, the management of the dangerous patient. Important areas of skill are the assessment of dangerousness, differential diagnosis, prodromal signs of psychotic decompensation, the predictors of violence, and the accepted behavioral and pharmacologic interventions for the acutely violent patient. Other emergency conditions such as assessment of suicidality in the adult and child (for the child psychiatry trainee) are also important areas of skill development. The child psychiatry trainee will also demonstrate competence in the management of specific childhood emergencies such as potential to run away and school refusal.

\section{REFERENCES}

Cavanaugh S: Psychiatric emergencies. Medical Clinics of North America 70(5): 11851202, 1986

Conn LM, Lion JR: Pharmacologic approaches to violence. Psychiatric Clinics of North America 7(4): 879-886, 1984

Dubin WR, Weiss KJ, and Dorn JM: Pharmacotherapy of psychiatric emergencies. Journal of Clinical Pharmacology 6(4): 210-222, 1986

Werner PD, Rose TL, and Yesavage JA. Reliability, accuracy, and decision making strategy in clinical predictions of imminent dangerousness. Journal of Consultative and Clinical Psychology 51: 815-825, 1983

Shaffer D, Ehrhardt AA, Greenhill LL: The Clinical Guide to Child Psychiatry. The Free Press, New York, pp 167-180, 1985 
and foremost to use creativity to design an experience that fulfills his or her areas of personal interest as well as meeting the particular psychiatric needs of the site at which they have chosen to work. The resident's desire and ability to be creative is affected by the work site chosen because of the differing degrees of structure and psychopathology existing at each of the shelters.

The most difficult task by far has been the actual implementation and legitimization of the curriculum. At our institution, Walter Reed Army Medical Center and at the other three which are presently involved in the elective, the challenge has been to obtain the support of the Chief of the Department and the Director of Training in considering this elective as a worthwhile clinical experience and a viable alternative to already existing forms of training in community and emergency psychiatry. Paramount of all obstacles has been the difficulty in creating time in the already busy schedule of the resident, without sacrificing any of the existing training curriculum. There have been financial concerns as well with the private training programs. Who will pay the residents while they are providing services at the shelters, and who will make up for the lost billable hours at the private university outpatient clinics, were considerable problems to be overcome. Another important concern has been that the curriculum is designed so that the trainee works at a given site for 6 to 12 months for $1 / 2$ day per week. This format is difficult to fit into many existing residency programs given that the standard fourth year psychiatry elective provides 20 to 40 hours per week for a period of 1 to 4 months. This is too much time and too short a period to build working relationships with the homeless and the shelter staff to create a productive working coalition which is based on standard models of community psychiatry. Given that this is the first year that the curriculum has been implemented, the result has been a compromise for some of the residents. Some are participating in the elective on their own time in the evenings, while others have been able to create the time during the day to consult at one of the shelters.

\section{RESIDENTS' EXPERIENCES}

Upon entering the shelters, we were overwhelmed by the sense of disarray and the unstructured living conditions. Men and women were living separately in close proximity with little or no communication. Violent verbal, and sometimes physical, outbursts were common as territorial imperatives were exercised. A general sense of tension and a palpable lack of human relatedness pervaded the shelters. An identified worker or area was seen as the "control" area to whom or which problems or conflicts were brought for resolution. Crisis management, not prevention or program innovation, was the primary mode of operation at the shelters.

Crucial to the success of the training program was first identifying the person with authority in the shelter, and setting up regular meetings with that person. For each of us, this was a nurse or program director, who also had the 
longest institutional memory and who was clearly sought out by other workers for advice and conflict mediation. The first several meetings consisted of introductions, tours, and listening to the shelter workers describe what they felt were the central problems of working with homeless individuals. Initially, we were implicitly asked to do therapy for the workers. We expected this, in part, because of the countertransference issues which arise from working with the chronic mentally ill. We validated stress levels, listened to the sense of hopelessness and feelings of struggling against insurmountable odds (especially in relationship to child physical and sexual abuse and alcohol and/or drug abuse problems) which did more to encourage an initial dialogue, than rushing in with treatment concerns.

Through the meetings, we kept an open ear and eye to what we saw as problem areas in the shelter. In both of our respective shelters, we observed the lack of a general staff meeting designed to clarify issues, set agendas, review work schedules, and to provide for a generally supportive atmosphere in which to work. It was clear that not all workers had equal access to the person in charge of policy making and that most staff members had developed their own individual communication channels with this person. This often excluded, alienated, and angered other less resourceful, but equally competent workers. Much time was spent on taking care of momentary crises and thus, scheduled activities were all but non-existent. As a result, staff were generally demoralized. They had a sense of unfairness in the structure, were protective of free time, and vigilant, almost paranoid, towards other workers' sparse benefits and accolades. The process we observed appeared over time to be one in which the staff, feeling unsupported and drained, identified with the shelter inhabitants, thereby creating a chaotic atmosphere of splitting and projective identification.

Communication between workers in the shelters from shift to shift was poor. Log books contained information such as: " 29 October 1988, Sunday; Bill on duty; nothing happened," reflecting the general apathy of the staff and the devaluation of communication channels. It became common knowledge who would provide extra blankets and who would not. Certain staff members were hailed by inhabitants as "good guys"; while others appeared as outsiders and generally were regarded as ineffective by shelter inhabitants and staff. Inhabitants often searched out the "helpful" staff members who then became overworked and worn out by their own generosity and commitment, undermined by a lack of a firm vision of management.

Meetings continued, and each of us listened carefully to what was the identified needs of the shelter. "This guy is upset; would you talk to him?", was often an initial question. We reasoned that attempting to make this simple request more comprehensive would have been seen as elitist. As we were struggling with what our professional image would be in the shelter, so were the shelter operators. Opting for letting the workers define the needs initially enabled the development of a clear working relationship based on the answering of legitimate, although psychiatrically unsophisticated questions. Each question 
was used as an opportunity to educate and help workers identify for themselves legitimate psychiatric emergencies and referrals and to encourage a greater competence in dealing with often very acutely ill individuals and those with severe personality disorders. Gradually questions became more pertinent. Requests for evaluation of depression and psychosis yielded fruitful discussions on commitment and other referrals for medication and mental health services.

Throughout an initial three month period, we were often asked by workers to resolve interpersonal conflicts in the shelter. We had to be mindful of our role as consultants and facilitators and gear our interventions towards empowering workers, not fostering dependency. We often reframed questions of conflict among workers as a result of the intensity of the work with the homeless. We chose to redirect issues back to the legitimate authority base and also postulated the need for processing the work in the shelter among workers.

Gradually our presence was seen as beneficial and indeed there were fewer psychiatric emergencies as the comfort level of staff in dealing with psychopathology increased. At one shelter (R.K.), the police were called as many as 4-5 times a week for emergency commitments prior to the placement of a psychiatric resident there. After four or five months, emergency commitments were requested approximately once a week. At another (L.C.), the incidence of physical and verbal violence towards their own children decreased dramatically, as well as the incidence of nightmares and enuresis decreasing in the children after three months of consultation to the staff and group intervention with the mothers and their children. Our advice was sought in a number of different areas including staff management; after five months of weekly visits, the identified staff leader at one of the shelters asked me (R.K.) to lead a group of workers in an open discussion of what it is like to work with the homeless. In part from this endeavor, and its emphasis on countertransference issues and improving communication between workers, a general cooperative spirit emerged. Log books now contained detailed information of problems encountered on each shift and possible agenda items for the regularly scheduled staff meetings.

In summary, the presence of the resident had not only allowed for on-site psychiatric expertise in the evaluation and treatment of the homeless mentally ill and homeless families, but also has provided for staff development consultation and an opportunity to impact positively on an organization caring for, in many cases, seriously ill and generally marginated individuals. At the grass roots level the resident learns a powerful lesson in the experience of community mental health care and about those who care for the patients.

\section{REFERENCES}

1. Lamb HR, Talbot JA: The homeless mentally ill: The Perspective of the American Psychiatric Association. Am Journal of Psych 256(4): 498-501, 1986 
2. Snow DA, Baker SG, Anderson L, et al: The myth of pervasive mental illness among the homeless. Social Problems 33:407-423; 1986

3. Bachrach, LL: Geographic mobility and the homeless mentally ill. Hospital and Community Psychiatry 38(1): 27-28, 1987

4. Kanter AS: "Homeless mentally ill people: No longer out of sight and out of mind. New York Law School Human Rights Annual pp. 331-357, 1986

5. Carpenter B, Glymph Q: Draft Report: homelessness policy issue paper. Commission on Mental Health Services, Washington, DC, October 24, 1988

6. Main, TF: What we know about the homeless. Commentary May pp 26-31, 1988

7. Levine IS, Stockdill JW: Mentally ill and homeless: A national problem, in Treating the Homeless: Urban Psychiatry's Challenge. Edited by Jones B, Washington, DC, American Psychiatric Association Press, 1986

8. Test MA, Stein LI: Special living arrangements: A model for decision-making. Hospital and Community Psychiatry 28:608-610, 1977 